\title{
Phosphohistone H3 Immunohistochemical Labeling: a Potentially Useful Tool for Risk Stratification and Prognostic Analysis in Gastrointestinal Stromal Tumors.
}

\section{Xiaohong Li}

The First People's hospital of Zigong

Yutao Zhang ( $\square$ bondyzyt1999@163.com )

The First People's Hospital of Zigong

\section{Feng Li}

The First People's Hospital of Zigong

\section{Yun Tang}

The First People's Hospital of Zigong

Hongyuan Zhou

The First People's Hospital of Zigong

\section{Research}

Keywords: Gastrointestinal stromal tumor, Phosphohistone H3, Ki67, Immunohistochemistry, Mitotic index, Prognosis

Posted Date: September 7th, 2021

DOI: https://doi.org/10.21203/rs.3.rs-855963/v1

License: (a) (i) This work is licensed under a Creative Commons Attribution 4.0 International License. Read Full License 


\section{Abstract}

\section{Background}

It is well recognized that risk stratification of gastrointestinal stromal tumors (GISTs) is closely related to tumor size, mitotic index (Ml), and primary location. Among these three parameters, tumor size and primary location are easily established, while MI is subjective and its repeatability is poor. It is thus necessary to identify a biomarker to represent the true MI. Expression status and biological or prognostic significance of mitotic marker phosphohistone H3 (PHH3) and cell proliferation marker Ki67 in GIST have not been clearly understood until now.

\section{Methods}

An immunohistochemistry experiment was performed to detect the expression status of PHH3 and Ki67 in 125 paraffin-embedded GIST samples. All of the patients were followed up until September 30, 2019.

\section{Results}

The Ml determined using stained hematoxylin and eosin (H\&E) sections (MI-H\&E) and immunohistochemically positive $\mathrm{PHH} 3$ index $(\mathrm{PHH} 3-\mathrm{HHC})$ was compared among groups of different genders, ages, primary locations, and histological subtypes, showing that the difference was not statistically significant $(P>0.05)$. MI-H\&E and the immunohistochemically positive Ki67 index were positively correlated $(r=0.273, P=0.001)$, but the correlation was lower than that with the PHH3-positive index $(r=0.705, P=0.000)$. The PHH3-positive index was also positively correlated with the Ki67 index $(r=0.224, P=0.006)$. MI-H\&E were positively correlated with Ml quantified using immunohistochemically stained $\mathrm{PHH} 3$ sections $(\mathrm{MI}-\mathrm{PHH} 3)(P<0.05)$. After using $\mathrm{PHH} 3$ to perform Ml quantification, the risk stratification of five GIST cases was changed, where two cases were given a higher risk grade and three cases were given a lower risk grade. Follow-up data were obtained from 98 cases (98/125, 78.4\%), including two cases of metastasis and one death. Both metastatic and death cases had high MI-H\&E. One metastatic case and one death case had high $\mathrm{PHH} 3$-positive indexes, while the remaining metastatic case had a low PHH3-positive index.

\section{Conclusion}

Immunohistochemical PHH3 labeling is a potentially useful tool for risk stratification and prognostic analysis in GIST. Using immunohistochemical PHH3 labeling makes it more convenient for pathologists to determine the MI for GIST. MI quantification with immunohistochemical PHH3 sections can be used as an adjunct tool for risk stratification and prognostic analysis of GIST, but cannot completely replace MI quantification using stained H\&E sections. The Ki67 index is positively correlated with MI-H\&E, although the efficiency of tumor risk stratification is lower than that of $\mathrm{PHH} 3$.

\section{Highlights}


1. Immunohistochemical methods were used to detect the expression of $\mathrm{PHH} 3$ and $\mathrm{Ki} 67$ in the largest sample of GISTs (125 cases) to date, and high-quality follow-up data were obtained.

2. Immunohistochemically positive $\mathrm{PHH} 3$ index was positively correlated with both mitotic indexes determined using the H\&E-stained sections and immunohistochemically positive Ki67 index in GIST.

3. The role of PHH3 in risk stratification and prognostic analysis of GIST is equivalent to direct quantification of the mitotic index using H\&E-stained sections. The use of PHH3 immunohistochemical labeling makes it more convenient for pathologists to determine the mitotic index for GIST.

4. Mitotic index quantification with $\mathrm{PHH} 3$ immunohistochemical sections can be utilized as a useful tool for risk stratification and prognostic analysis of GIST, but cannot completely replace mitotic index quantification using H\&E-stained sections.

\section{Introduction}

Gastrointestinal stromal tumors (GISTs) are the most common non-epithelial tumors of the gastrointestinal tract. Compared to the epithelial tumors, the incidence of GISTs is lower. GIST presentation is insidious at the onset of the disease. Some patients have almost no clinical symptoms and the tumor is often detected during a routine physical examination or in association with other diseases. The incidence of GIST ranges from 6.8 to 20 per million people in different countries [1]. GIST can range from benign to malignant according to its biological behavior. The National Institutes of Health $(\mathrm{NIH})$ classifies tumor risk stratification of GIST into four levels: very low risk, low risk, moderate risk, and high risk. At present, according to the modified GIST classification standard of NIH 2008, GIST risk stratification is closely correlated with tumor size, mitotic index (MI), and primary location.

Among the factors affecting GIST grading, MI quantification often differs among observers. Although there are some markers reflecting the proliferation index, none of them can correctly represent MI. Phosphohistone $\mathrm{H} 3$ (PHH3) is a newly studied eukaryotic core histone. Histone $\mathrm{H} 3$ begins to be phosphorylated in the mitotic $\mathrm{G} 2$ phase and dephosphorylated at the end of the mitotic (M) phase. Therefore, PHH3 is expressed in mitotic $\mathrm{G} 2$ and M phases [2, 3]. Since Hendzel et al. [2] first proposed using $\mathrm{PHH} 3$ as a mitotic marker in 1997, research on $\mathrm{PHH} 3$ in different tumors has been continuously reported. However, the expression status and significance of PHH3 in GIST have rarely been reported until now. The present study used immunohistochemical $(\mathrm{IHC})$ staining to explore the expression and significance of the mitotic marker PHH3 and cell proliferation marker Ki67 in GIST. The relationship among the expression status of PHH3 and Ki67, clinicopathological characteristics, tumor risk stratification, and prognosis in GIST was analyzed.

\section{Materials And Methods}

\subsection{Patients and tissue samples}


The present study was performed with Institutional Review Board's approval and all patients provided informed consent. A total of 125 consecutive, formalin-fixed, and paraffin-embedded GIST samples with different grading were obtained from patients who had undergone an operation between January 2012 and December 2017 in the First People's Hospital of Zigong and between January 2016 and December 2018 in the Fourth People's Hospital of Zigong. None of the patients were administered treatment before the operation. Pathological diagnosis of all cases was confirmed by histomorphology and IHC staining. The haematoxylin-eosin (H\&E)-stained sections were reviewed and the MI was independently re-calculated by two experienced pathologists before the experiment.

\subsection{Methods}

\subsubsection{IHC}

IHC staining was performed using an automatic IHC staining apparatus (Bench Mark GX, Roche, USA). Both polyclonal PHH3 antibody and monoclonal Ki67 antibody (clone number MIB-1) were purchased from Maixin Biotechnology Company (Fuzhou, China). Both antibodies were ready-to-use. Samples without primary antibodies were used as a blank control. Human lung adenocarcinoma tissue sections were used as a positive control.

\subsubsection{Quantitative analysis of MI, PHH3-positive index, and Ki67 index}

Evaluation of Ml using H\&E-stained sections (MI-H\&E), PHH3-positive index, and Ki67 was performed sequentially in the same section areas. These parameters were observed using a light microscope (Olympus BX43, field number: $22 \mathrm{~mm}$ ). Two experienced pathologists chose a "hot spot" region to continuously observe 21 high-power fields $\left(5 \mathrm{~mm}^{2}\right.$ ) and counted mitotic figures in the same area on H\&Estained and PHH3 IHC-stained sections. The Ki67-positive index was calculated as the percentage of positive cells in a continuous counting of 1000 cells.

\subsubsection{Result interpretation}

The mean values for MI-H\&E and $\mathrm{PHH} 3 \mathrm{IHC}$ evaluated by two pathologists were recorded. $\mathrm{PHH} 3-$ positive cells taking up $\leq 5 / 5 \mathrm{~mm}^{2}$ on immunohistochemically stained sections had a low expression, while those taking up $>5 / 5 \mathrm{~mm}^{2}$ had a high expression. The percentage of Ki67-positive cells of $\leq 5 \%$ was recorded as low expression, while that of $>5 \%$ was recorded as high expression. On H\&E-stained sections, the mitotic figure of $\leq 5 / 5 \mathrm{~mm}^{2}$ was regarded as low MI (LMI), while $>5 / 5 \mathrm{~mm}^{2}$ was regarded as high $\mathrm{Ml}(\mathrm{HMI})$.

\subsubsection{GIST risk stratification}

The GIST risk stratification was performed according to the $2008 \mathrm{NIH}$ modified GIST classification standard.

\subsection{Follow-up}

The follow-up was conducted on all included patients via telephone with a deadline of September 30, 2019. 


\subsection{Statistical analysis}

SPSS 23.0 (SPSS, Chicago, IL, USA) statistical software was used to perform the $\chi 2$ test on the classification data. One-way analysis of variance (ANOVA) was used for the comparison between groups. Spearman's correlation test was used for correlation analysis between different groups. A $P$-value of $<0.05$ was considered to indicate statistical significance.

\section{Results}

\subsection{Clinicopathological characteristics}

There were 45 males and 80 females (male/female $=0.56 / 1$ ) in 125 cases of primary GISTs. Patients' age ranged from 16 to 84 years, while median and average ages were 62 and 61.2 years, respectively. Primary locations included the stomach $(88 / 125,70.4 \%)$, intestine $(29 / 125,23.2 \%)$, and parenteral location $(8 / 125$, $6.4 \%$ ). Tumor sizes ranged from 0.3 to $34 \mathrm{~cm}$, and the average diameter was $4.99 \mathrm{~cm}$. There were three histological subtypes, including mixed cell type (10/125, 8.0\%), epithelial-like cell type (11/125, 8.8\%), and spindle cell type (104/125, 83.2\%). Follow-up data were obtained from 98 cases $(98 / 125,78.4 \%)$, including two metastasis cases and one death.

\subsection{Relationship between MI-H\&E and clinicopathological characteristics of GIST}

For MI-H\&E, there were 19 GIST cases of HMI (19/125, 15.2\%). MI-H\&E were compared among groups of different genders, ages, locations, and histological subtypes, showing that the difference was not statistically significant $(P>0.05$; Table 1$)$. 
Table 1

Relationship between MI-H\&E and clinicopathological characteristics of GIST

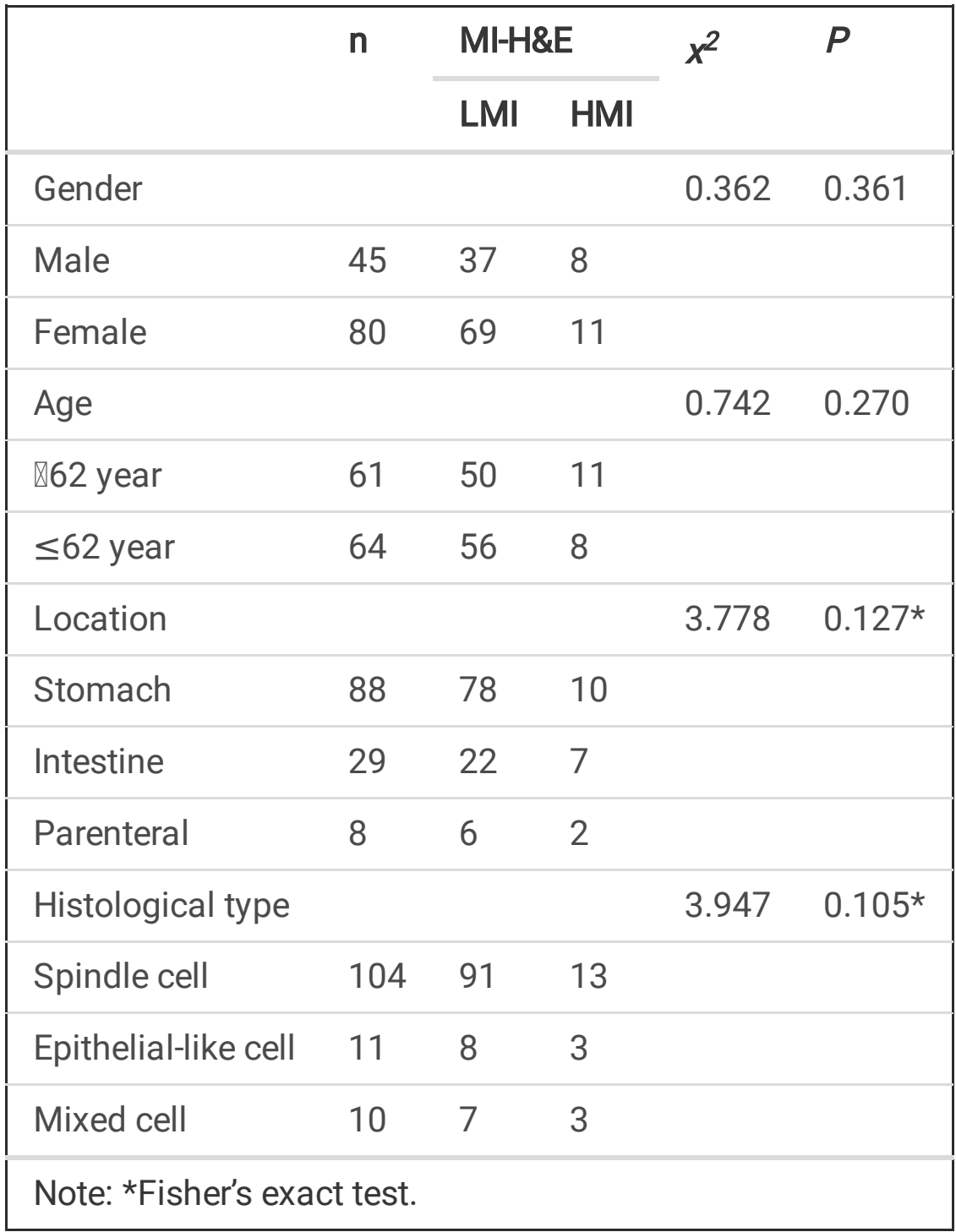

\subsection{Relationship between PHH3-positive index and clinicopathological characteristics of GIST}

Immunolocalization of PHH3 was observed in the nuclei of GIST cells (Fig. 1). There were 16 GIST cases with a high PHH3-positive index (16/125, 12.8\%). The PHH3-positive index was compared among groups of different genders, ages, locations, and histological subtypes, but the difference was not statistically significant $(P>0.05$; Table 2$)$. 
Table 2

Relationship between PHH3-positive index and clinicopathological characteristics of GIST

\begin{tabular}{|c|c|c|c|c|c|}
\hline \multirow{2}{*}{ 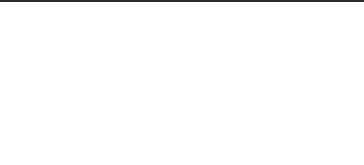 } & \multirow[t]{2}{*}{$\mathrm{n}$} & \multicolumn{2}{|c|}{ PHH3 positive index } & \multirow[t]{2}{*}{$x^{2}$} & \multirow[t]{2}{*}{$P$} \\
\hline & & Low & High & & \\
\hline Gender & & & & 0.018 & 0.550 \\
\hline Male & 45 & 39 & 6 & & \\
\hline Female & 80 & 70 & 10 & & \\
\hline Age & & & & 0.405 & 0.355 \\
\hline \62 year & 61 & 52 & 9 & & \\
\hline$\leq 62$ year & 64 & 57 & 7 & & \\
\hline Location & & & & 1.680 & $0.413^{*}$ \\
\hline Stomach & 88 & 78 & 10 & & \\
\hline Intestine & 29 & 25 & 4 & & \\
\hline Parenteral & 8 & 6 & 2 & & \\
\hline Histological type & & & & 3.684 & $0.114^{*}$ \\
\hline Spindle cell & 104 & 93 & 11 & & \\
\hline Epithelial-like cell & 11 & 9 & 2 & & \\
\hline Mixed cell & 10 & 7 & 3 & & \\
\hline Note: *Fisher's exa & t test. & & & & \\
\hline
\end{tabular}

\subsection{Correlation between MI-H\&E and PHH3-positive index and $\mathrm{Ki} 67$ index in GIST}

In 125 cases of GIST, there were 19 cases with an $\mathrm{HMI}$ and 16 cases with a high PHH3-positive index. A total of 13 MI-H\&E with HMI had a high PHH3-positive index, while 103 MI-H\&E with LMI had a low PHH3positive index. MI-H\&E and $\mathrm{PHH} 3 \mathrm{IHC}$ had a significantly positive correlation $(r=0.705, P=0.000)$ as demonstrated using the Spearman's correlation analysis (Table 3). Ki67 was positive in the nuclei of GIST cells (Fig. 2), and 65 GIST cases had a high Ki67 index (65/125, 52\%). A total of 16 cases with HMI had a high Ki67 index, and 57 cases with LMI had a low Ki67 index. Spearman's correlation analysis results revealed that the Ki67 index and MI-H\&E were positively correlated $(r=0.273, P=0.001)$ (Table 4), but the correlation was lower than that with the PHH3-positive index. 
Table 3

Correlation analysis between MI-H\&E and PHH3-positive index in GIST

\begin{tabular}{|c|c|c|c|c|c|}
\hline \multirow[t]{2}{*}{ MI-H\&E } & \multicolumn{2}{|c|}{$\mathrm{PHH} 3$ positive index } & \multirow[t]{2}{*}{ Total } & \multirow[t]{2}{*}{$r$} & \multirow[t]{2}{*}{$P$} \\
\hline & Low & High & & & \\
\hline LMI & 103 & 3 & 106 & & \\
\hline HMI & 6 & 13 & 19 & 0.705 & 0.000 \\
\hline Total & 109 & 16 & 125 & & \\
\hline
\end{tabular}

Table 4

Correlation analysis between MI-H\&E and Ki67 index in GIST

\begin{tabular}{|llllll|}
\hline MI-H\&E & \multicolumn{2}{l}{ Ki67 index } & Total & $\boldsymbol{r}$ & $\boldsymbol{P}$ \\
\cline { 2 - 4 } & Low & High & & & \\
\hline LMI & 57 & 49 & 106 & & \\
\hline HMI & 3 & 16 & 19 & 0.273 & $\mathbf{0 . 0 0 1}$ \\
\hline Total & 60 & 65 & 125 & & \\
\hline
\end{tabular}

\subsection{Correlation between PHH3-positive index and Ki67 index}

In the 125 GISTs, 13 cases with a high PHH3-positive index had a high Ki67 index, and 57 cases with a low PHH3-positive index had a low Ki67 index. Spearman's correlation analysis results revealed that the PHH3positive index was positively correlated with the Ki67 index ( $r=0.224, P=0.006$; Table 5).

Table 5

Correlation analysis between PHH3-positive index and Ki67 index

\begin{tabular}{|cccccc|}
\hline PHH3 & \multicolumn{3}{l}{ Ki67 index } & & \\
positive index & Low & High & Total & $r$ & $P$ \\
\hline Low & 57 & 52 & 109 & & \\
\hline High & 3 & 13 & 16 & 0.224 & $\mathbf{0 . 0 0 6}$ \\
\hline Total & 60 & 65 & 125 & & \\
\hline
\end{tabular}




\subsection{Correlation among MI-H\&E, PHH3-positive index, and prognosis in GIST}

Follow-up data were obtained from 98 cases (98/125, 78.4\%), including two cases of metastasis and one death. Follow-up ranged from 12 to 81 months, with a mean follow-up of 38.5 months. Both metastatic and death cases had a high MI-H\&E. For the two metastatic cases, one had a high PHH3-positive index, while the other had a low PHH3-positive index. The death case had a high PHH3-positive index too. According to the Spearman's correlation analysis result, patient prognosis was positively correlated with both MI-H\&E and PHH3-IHC ( $r=0.506, P=0.000 ; r=0.314, P=0.001$, respectively; Table 6$)$. In addition, patient prognosis was also positively correlated with the Ki67 index ( $r=0.171, P=0.047$; Table 7), although this correlation was lower compared to both MI-H\&E and PHH3-IHC.

Table 6

Relationship among MI-H\&E, PHH3-positive index, and prognosis in GIST

\begin{tabular}{|c|c|c|c|c|c|c|c|c|}
\hline \multirow[t]{2}{*}{ Prognosis } & \multicolumn{2}{|c|}{ MI-H\&E } & \multirow[t]{2}{*}{$r$} & \multirow[t]{2}{*}{$P$} & \multicolumn{2}{|c|}{ PHH3 positive index } & \multirow[t]{2}{*}{$r$} & \multirow[t]{2}{*}{$P$} \\
\hline & LMI & HMI & & & Low & High & & \\
\hline Alive & 85 & 10 & & & 86 & 9 & & \\
\hline Metastasis & 0 & 2 & 0.506 & 0.000 & 1 & 1 & 0.314 & 0.001 \\
\hline Death & 0 & 1 & & & 0 & 1 & & \\
\hline
\end{tabular}

Table 7

\begin{tabular}{|c|c|c|c|c|}
\hline \multirow[t]{2}{*}{ Prognosis } & \multicolumn{2}{|c|}{ Ki67 index } & \multirow[b]{2}{*}{$r$} & \multirow[b]{2}{*}{$P$} \\
\hline & Low & High & & \\
\hline Alive & 47 & 48 & & \\
\hline Metastasis & 0 & 2 & 0.171 & 0.047 \\
\hline Death & 0 & 1 & & \\
\hline
\end{tabular}

\subsection{MI quantification comparison between two groups}

In the present study, two experienced pathologists determined the Ml using double-blind reviewing of the enrolled cases. MI-H\&E and $\mathrm{PHH} 3-\mathrm{IHC}$ results determined by the two pathologists were evaluated using univariate analysis. There was no statistical difference $(P>0.05)$. 


\subsection{Difference in GIST risk grading depends on MI-H\&E and $\mathrm{PHH} 3-\mathrm{IHC}$}

MI quantification and risk grading were performed on both H\&E-stained sections and PHH3 IHC-stained sections, respectively. In 125 GIST cases, the risk stratification of five cases was changed and two cases were given a higher risk grade. These cases went from a very low-risk to moderate-risk and from moderaterisk to high-risk. The other three cases received a lower risk grading, where two cases were changed from high-risk to moderate-risk and one case was changed from high-risk to low-risk (Table 8).

Table 8

Differences in GIST risk grading depend on MI-H\&E and PHH3-IHC

\begin{tabular}{|c|c|c|c|c|c|c|c|c|}
\hline Case & Gender & $\begin{array}{l}\text { Age } \\
\text { (year) }\end{array}$ & $\begin{array}{l}\text { Primary } \\
\text { tumor } \\
\text { location }\end{array}$ & $\begin{array}{l}\text { Diameter } \\
(\mathrm{cm})\end{array}$ & $\begin{array}{l}\text { MI-H\&E } \\
\left(/ 5 \mathrm{~mm}^{2}\right)\end{array}$ & $\begin{array}{l}\text { Risk } \\
\text { grading } \\
\text { dependent } \\
\text { on MI-H\&E }\end{array}$ & $\begin{array}{l}\text { PHH3-IHC } \\
\left(/ 50 \mathrm{~mm}^{2}\right)\end{array}$ & $\begin{array}{l}\text { Risk } \\
\text { grading } \\
\text { dependent } \\
\text { on PHH3- } \\
\text { IHC }\end{array}$ \\
\hline 1 & Male & 72 & stomach & 2.0 & 4 & $\begin{array}{l}\text { very low } \\
\text { risk }\end{array}$ & 7 & $\begin{array}{l}\text { moderate } \\
\text { risk }\end{array}$ \\
\hline 2 & Female & 62 & stomach & 7.0 & 3 & $\begin{array}{l}\text { moderate } \\
\text { risk }\end{array}$ & 6 & high risk \\
\hline 3 & Female & 78 & stomach & 8.5 & 72 & high risk & 0 & $\begin{array}{l}\text { moderate } \\
\text { risk }\end{array}$ \\
\hline 4 & Male & 53 & stomach & 6.5 & 18 & high risk & 3 & $\begin{array}{l}\text { moderate } \\
\text { risk }\end{array}$ \\
\hline 5 & Female & 66 & rectum & 5.0 & 6 & high risk & 2 & low risk \\
\hline
\end{tabular}

\section{Discussion}

GIST is the most common mesenchymal tumor of the gastrointestinal tract. Most GISTs are activated due to mutations of c-kit proto-oncogene or platelet-derived growth factor receptor alpha gene. Its immunophenotype is positive for CD117, CD34, and DOG-1. The biological behavior of GIST has malignant potential and it is difficult to assess its prognosis accurately. The $2008 \mathrm{NIH}$ modified assessment system is usually used to evaluate the postoperative recurrence risk of primary and resectable GISTs. The test parameters include primary location, tumor size, MI, and tumor rupture. Among these parameters, primary location, tumor size, and tumor rupture are easily established, while MI quantification is performed more subjectively and its repeatability is poor. However, MI determination in GIST or other soft tissue tumors is less repeatable among observers due to the diverse morphological manifestation of mitosis and maldistribution in tumors [4, 5]. In addition, accurate quantification of mitosis on H\&E-stained sections depends on the ability to locate "hot spot" regions with the highest mitosis rate and to identify true mitosis from apoptotic cells and nuclei fragments. Furthermore, this may underestimate $\mathrm{Ml}$ in some cases and 
result in false assessment of biological behavior of GIST if the definition of mitosis is too strict [6]. Therefore, it is necessary to identify a biomarker to represent the true status of the MI.

A histone is an important component of the nucleosome, which is a basic unit of chromatin in eukaryotes. Researchers have identified five types of histones, including $\mathrm{H} 1, \mathrm{H} 2 \mathrm{~A}, \mathrm{H} 2 \mathrm{~B}, \mathrm{H} 3$, and $\mathrm{H} 4$ [7]. Histones $\mathrm{H} 2 \mathrm{~A}$, $\mathrm{H} 2 \mathrm{~B}, \mathrm{H} 3$, and $\mathrm{H} 4$ can be phosphorylated under the effect of protein kinases. The modified sites of histone $\mathrm{H} 3$ protein are positions 3 and 11 of threonine and positions 10 and 28 of serine. In the process of mitosis, histone $\mathrm{H} 3$ begins to phosphorylate in the late $\mathrm{G} 2$ phase and diffuses to the entire chromosome as mitosis progresses. The phosphorylation reaches a peak level in the $\mathrm{M}$ phase, while dephosphorylation occurs at the end of the $\mathrm{M}$ phase. The phosphorylation degree of histone $\mathrm{H} 3$ is very low in the interphase, which means that phosphorylated histone $\mathrm{H} 3(\mathrm{PHH} 3)$ is mainly expressed in $\mathrm{G} 2$ and $\mathrm{M}$ phases [2, 3]. At present, many studies consider that $\mathrm{PHH} 3$ is a specific mitotic marker, which can help to distinguish mitosis, nuclear fragments, and apoptotic cells in tissue sections [8]. It can be easier and quicker to perform mitosis quantification objectively in meningiomas by detecting the expression status of PHH3. This test has important value for assessing meningioma prognosis [9-12]. Similarly, the histological grading of breast cancer has been changed by quantifying mitosis with $\mathrm{PHH} 3$ labeling. The $\mathrm{PHH} 3$ expression status is closely related to the prognosis of breast cancer [13-16]. In addition, MI quantification using MI-H\&E has a strong correlation with PHH3-labeled MI in breast fibrous epithelial tumors, which can make MI quantification more convenient and is an important tool for diagnosis. In addition, researchers have discovered that $\mathrm{PHH} 3$-positive index has a significant correlation with tumor grading and prognosis in uterine smooth muscle tumor [17], astrocytoma [18-19], malignant melanoma [20-21], esophageal squamous cell carcinoma [22], ovarian serous adenocarcinoma [23], and other tumors.

$\mathrm{Ki} 67$ is a nuclear proliferation antigen that is expressed in all cell cycle phases, except for G0 phase, and is widely used to evaluate the proliferative activity of tumor cells. The Ki67-positive cells are not necessarily occurring in the M phase because Ki67 is expressed in all cell cycle phases, except for the G0 phase [24]. Although studies have shown that Ki67 is related to biological behavior of GIST, there is no system that uses it as an evaluation parameter for GIST grading [25-28]. Moreover, using it will result in overestimation of tumor proliferation activity because infiltrating lymphocytes in the tumor may also have an immunoreaction to Ki67.

The present study evaluated the relationship between MI-H\&E and PHH3-positive index and clinicopathological characteristics of 125 cases of GIST. There were no statistically significant differences among MI-H\&E, PHH3-positive index, and groups of different gender, age, primary location, and histological subtype. Correlation analysis showed that the PHH3-positive index has a good correlation with $\mathrm{MI}-\mathrm{H} \& \mathrm{E}$, which is consistent with previous research results [29-30]. Similarly, Ki67 index is correlated with MI-H\&E. In the 125 cases of GIST, both PHH3 and Ki67 had a high expression in 13 cases and low expression in 57 cases. Correlation analysis results showed that the Ki67 index was positively correlated with the PHH3positive index, but the correlation was lower than that between the PHH3-positive index and MI-H\&E. This is due to the fact that Ki67 is expressed in all cell cycles except the G0 phase and Ki67 is also expressed by inflammatory cells in tumors. Comparatively, $\mathrm{PHH} 3$ is mainly expressed in the $\mathrm{G} 2$ and $\mathrm{M}$ phases and can represent cell mitosis status more accurately. 
For a metastatic GIST in the present study, MI-H\&E $\left(31 / 5 \mathrm{~mm}^{2}\right)$ revealed a higher value than the PHH3positive index $\left(1 / 5 \mathrm{~mm}^{2}\right)$. The tumor risk stratification of this case has not been changed because the GIST was large enough in diameter $(16 \mathrm{~cm})$ to be graded as high-risk and therefore did not depend on the $\mathrm{MI}$ value for evaluation. However, correlation between MI-H\&E and prognosis is better than that with the PHH3positive index in prognosis analysis of this special case. There are two possible reasons for this. First, false negative results during immunohistochemical staining may be due to various factors, such as insufficient tissue fixation or improper operating procedure. Second, apoptotic cells or nuclear fragments affect the mitosis interpretation on H\&E-stained sections. Our data show that the Ki67 index is related to GIST prognosis as well, which is consistent with previous research [25-28]. This suggests that both $\mathrm{PHH} 3$ and Ki67 are prognostic markers of GIST.

In the present study, tumor risk stratification of five cases was changed due to $\mathrm{PHH}$-IHC results. Compared to $\mathrm{MI}$ quantification using $\mathrm{H} \& \mathrm{E}-\mathrm{stained}$ sections, two cases received a higher risk classification and three cases received a lower risk classification based on PHH3-IHC results. It is more difficult to accurately determine the "hot spot" regions and evaluate mitosis on H\&E-stained sections due to interference from apoptotic cells and nuclear fragments [31]. This may lead to MI-H\&E producing values that are higher than those for the PHH3-positive index, resulting in higher tumor risk stratification using H\&E-stained sections. By contrast, it is easy to identify the "hot spot" mitosis regions and distinguish real mitosis in a lowerpowered field using $\mathrm{PHH} 3 \mathrm{IHC}$ staining. Therefore, it is more convenient and accurate to evaluate mitosis using $\mathrm{PHH} 3$-stained $\mathrm{IHC}$ sections. However, the false negative $\mathrm{PHH} 3 \mathrm{IHC}$ staining results may also affect mitosis quantification due to various factors [32-35]. Previous studies on $\mathrm{PHH} 3$ expression in malignant tumors have shown that $\mathrm{PHH} 3-\mathrm{IHC}$ is highly correlated with $\mathrm{MI}-\mathrm{H} \& \mathrm{E}$, although it is slightly higher than MI$\mathrm{H} \& \mathrm{E}$. However, only H\&E-stained sections can be used to perform mitosis quantification during risk stratification of GIST at this time [36-38]. For this reason, using PHH3-stained IHC sections to perform mitosis evaluation may lead to grading changes in tumor risk stratification of GIST and affect further therapy. Accordingly, MI quantification using PHH3-stained IHC sections can be used as an assistive tool, rather than a replacement, for tumor risk stratification of GIST when a pathological diagnosis is made.

In summary, $\mathrm{PHH} 3-$ positive IHC index is positively correlated with $\mathrm{MI}-\mathrm{H} \& \mathrm{E}$, which is a more pronounced relationship than that between Ki67 in GIST. PHH3 can play an assistive role in evaluation of risk stratification and prognosis in GIST. MI determined using PHH3-stained IHC sections can be used as an assistive tool, but not a replacement, for tumor risk stratification of GIST using H\&E-stained sections.

\section{Conclusion}

PHH3 IHC labeling is a potentially useful tool for risk stratification and prognostic analysis in GIST. The use of $\mathrm{PHH} 3 \mathrm{IHC}$ labeling makes it more convenient for pathologists to determine the MI for GIST. MI quantification using $\mathrm{PHH} 3 \mathrm{IHC}$ sections can be used as an adjunct tool for risk stratification and prognostic analysis of GIST, but cannot completely replace MI quantification using H\&E-stained sections. The Ki67 index is positively correlated with MI-H\&E, but its efficiency for tumor risk stratification is lower than that of $\mathrm{PHH} 3$. 


\section{Declarations}

\section{Acknowledgement}

We thank Dr. Yong Wang from the Department of Pathology, Fourth People's Hospital of Zigong, China for providing help in this research work. This study was supported by the Key Science and Technology Project of Zigong City (No. 2017ZC44).

\section{Footnotes}

Institutional review board statement: This study was reviewed and approved by the Ethics Committee of The First People's Hospital of Zigong.

Informed consent statement: Patients were required to give informed consent to this study.

Conflict-of-interest statement: We have no financial relationships to disclose.

\section{Author contributions}

Xiaohong Li and Yutao Zhang designed this research work and wrote the paper. Feng Li and Xiaohong Li performed the immunohistochemistry experiments and follow-up works. Yun Tang and Hongyuan Zhou reviewed the slides and evaluated experimental results. Xiaohong Li did the statistical analysis.

\section{Supported by}

Key Science and Technology Project of Zigong City (No. 2017ZC44)

\section{References}

1. Jian Wang, Xiongzeng Zhu. Pathology of soft tissue tumors, second edition [M]. People's Medical Publishing House, 2017:603.

2. Hendzel MJ, Wei Y, Mancini MA, Van Hooser A, Ranalli T, Brinkley BR, Bazett-Jones DP, Allis CD. Mitosis-specific phosphorylation of histone $\mathrm{H} 3$ initiates primarily within pericentromeric heterochromatin during $\mathrm{G} 2$ and spreads in an ordered fashion coincident with mitotic chromosome condensation. Chromosoma. 1997;106(6):348-60. doi: 10.1007/s004120050256. PMID: 9362543.

3. Villani V, Mahadevan KK, Ligorio M, Fernández-Del Castillo C, Ting DT, Sabbatino F, Zhang I, Vangel M, Ferrone S, Warshaw AL, Lillemoe KD, Wargo J, Deshpande V, Ferrone CR. Phosphorylated Histone H3 (PHH3) Is a Superior Proliferation Marker for Prognosis of Pancreatic Neuroendocrine Tumors. Ann Surg Oncol. 2016;23(Suppl 5):609-617. doi: 10.1245/s10434-016-5171-x. PMID: 27020585.

4. Hasegawa T, Yamamoto S, Nojima T, Hirose T, Nikaido T, Yamashiro K, Matsuno Y. Validity and reproducibility of histologic diagnosis and grading for adult soft-tissue sarcomas. Hum Pathol. 2002;33(1):111-5. doi: 10.1053/hupa.2002.30184. PMID: 11823981. 
5. Yamaguchi U, Hasegawa T, Sakurai S, Sakuma Y, Takazawa Y, Hishima T, Mitsuhashi T, Sekine S, Chuman $\mathrm{H}$, Shimoda T. Interobserver variability in histologic recognition, interpretation of KIT immunostaining, and determining MIB-1 labeling indices in gastrointestinal stromal tumors and other spindle cell tumors of the gastrointestinal tract. Appl Immunohistochem Mol Morphol. 2006;14(1):4651. doi: 10.1097/01.pai.0000151023.88969.d7. PMID: 16540730.

6. Alkhasawneh A, Reith JD, Toro TZ, Ayed AO, Lu X, George TJ, Duckworth LV. Interobserver variability of mitotic index and utility of $\mathrm{PHH} 3$ for risk stratification in gastrointestinal stromal tumors. Am J Clin Pathol. 2015;143(3):385-92. doi: 10.1309/AJCPAPH28VHZEKNQ. Erratum in: Am J Clin Pathol. 2015;143(5):760. PMID: 25696796.

7. Suganuma T, Workman JL. Signals and combinatorial functions of histone modifications. Annu Rev Biochem. 2011; 80:473-99. doi: 10.1146/annurev-biochem-061809-175347. PMID: 21529160.

8. Schimming TT, Grabellus F, Roner M, Pechlivanis S, Sucker A, Bielefeld N, Moll I, Schadendorf D, Hillen $\mathrm{U}$. pHH3 immunostaining improves interobserver agreement of mitotic index in thin melanomas. Am J Dermatopathol. 2012;34(3):266-9. doi: 10.1097/DAD.0b013e31823135a3. PMID: 22197861.

9. Winther TL, Arnli MB, Salvesen $\varnothing$, Torp SH. Phosphohistone-H3 Proliferation Index Is Superior to Mitotic Index and MIB-1 Expression as a Predictor of Recurrence in Human Meningiomas. Am J Clin Pathol. 2016;146(4):510-20. doi: 10.1093/ajcp/aqw141. PMID: 27686177.

10. Puripat $\mathrm{N}$, Loharamtaweethong K. Phosphohistone $\mathrm{H} 3(\mathrm{PHH} 3)$ as a surrogate of mitotic figure count for grading in meningiomas: a comparison of $\mathrm{PHH} 3$ (S10) versus $\mathrm{PHH} 3$ (S28) antibodies. Virchows Arch. 2019;474(1):87-96. doi: 10.1007/s00428-018-2458-2. PMID: 30267302.

11. Maier AD, Bartek J Jr, Eriksson F, Ugleholdt H, Juhler M, Broholm H, Mathiesen TI. Clinical and histopathological predictors of outcome in malignant meningioma. Neurosurg Rev. 2020;43(2):643653. doi: 10.1007/s10143-019-01093-5. Epub 2019 Mar 13. PMID: 30868425.

12. Ozek E, Akdag H, Tosuner Z, Abdallah A, Hatiboglu MA. The correlation between phosphorylated Histone H3 (PHH3) and p-STAT3 in Meningiomas. Clin Neurol Neurosurg. 2019; 178:46-50. doi: 10.1016/j.clineuro.2019.01.016. PMID: 30710729.

13. Bossard C, Jarry A, Colombeix C, Bach-Ngohou K, Moreau A, Loussouarn D, Mosnier JF, Laboisse CL. Phosphohistone $\mathrm{H} 3$ labelling for histoprognostic grading of breast adenocarcinomas and computerassisted determination of mitotic index. J Clin Pathol. 2006;59(7):706-10. doi:

10.1136/jcp.2005.030452. PMID: 16461563; PMCID: PMC1860410.

14. Cui X, Harada S, Shen D, Siegal GP, Wei S. The Utility of Phosphohistone H3 in Breast Cancer Grading. Appl Immunohistochem Mol Morphol. 2015;23(10):689-95. doi: 10.1097/PAl.0000000000000137. PMID: 25611243.

15. Skaland I, Janssen EA, Gudlaugsson E, Klos J, Kjellevold KH, Søiland H, Baak JP. Phosphohistone H3 expression has much stronger prognostic value than classical prognosticators in invasive lymph nodenegative breast cancer patients less than 55 years of age. Mod Pathol. 2007;20(12):1307-15. doi: 10.1038/modpathol.3800972. PMID: 17917671.

16. Lee LH, Swanson PE, Tang PA, Bigras G, Yang H. Association Between Phosphorylated Histone H3 and Oncotype DX Recurrence Scores in Breast Cancer. Appl Immunohistochem Mol Morphol. 
2017;25(1):25-31. doi: 10.1097/PAI.0000000000000261. PMID: 26371428; PMCID: PMC5147033.

17. Chow KL, Tse KY, Cheung CL, Wong KW, Cheung AN, Wong RW, Chan AN, Yuen NW, Ngan HY, Ip PP. The mitosis-specific marker phosphohistone-H3 $(\mathrm{PHH} 3)$ is an independent prognosticator in uterine smooth muscle tumours: an outcome-based study. Histopathology. 2017;70(5):746-755. doi: 10.1111/his.13124. PMID: 27864989.

18. Habberstad AH, Gulati S, Torp SH. Evaluation of the proliferation markers Ki-67/MIB-1, mitosin, survivin, pHH3, and DNA topoisomerase Ila in human anaplastic astrocytomas-an immunohistochemical study. Diagn Pathol. 2011; 6:43. doi: 10.1186/1746-1596-6-43. PMID: $21609421 ;$ PMCID: PMC3127815.

19. Varughese RK, Lind-Landström T, Habberstad AH, Salvesen $\emptyset$, Haug CS, Sundstrøm S, Torp SH. Mitosin and pHH3 predict poorer survival in astrocytomas WHO grades II and III. J Clin Pathol. 2016;69(1):26-34. doi: 10.1136/jclinpath-2015-202983. PMID: 26188054.

20. Tetzlaff MT, Curry JL, Ivan D, Wang WL, Torres-Cabala CA, Bassett RL, Valencia KM, McLemore MS, Ross MI, Prieto VG. Immunodetection of phosphohistone H3 as a surrogate of mitotic figure count and clinical outcome in cutaneous melanoma. Mod Pathol. 2013;26(9):1153-60. doi: 10.1038/modpathol.2013.59. PMID: 23558574.

21. Nielsen PS, Riber-Hansen R, Schmidt H, Steiniche T. Automated quantification of proliferation with automated hot-spot selection in phosphohistone H3/MART1 dual-stained stage I/II melanoma. Diagn Pathol. 2016; 11:35. doi: 10.1186/s13000-016-0484-4. PMID: 27062658; PMCID: PMC4826493.

22. Nakashima S, Shiozaki A, Ichikawa D, Komatsu S, Konishi H, litaka D, Kubota T, Fujiwara H, Okamoto K, Kishimoto M, Otsuji E. Anti-phosphohistone H3 as an independent prognostic factor in human esophageal squamous cell carcinoma. Anticancer Res. 2013;33(2):461-7. PMID: 23393337.

23. Scott IS, Heath TM, Morris LS, Rushbrook SM, Bird K, Vowler SL, Arends MJ, Coleman N. A novel immunohistochemical method for estimating cell cycle phase distribution in ovarian serous neoplasms: implications for the histopathological assessment of paraffin-embedded specimens. $\mathrm{Br} \mathrm{J}$ Cancer. 2004;90(8):1583-90. doi: 10.1038/sj.bjc.6601660. PMID: 15083189; PMCID: PMC2409706.

24. Filiz G, Yalçinkaya O, Gürel S, Yerci O, Memik F. The relationship between MIB-1 proliferative activity and mitotic index in gastrointestinal stromal tumors. Hepatogastroenterology. 2007;54(74):438-41. PMID: 17523292.

25. Nagasako Y, Misawa K, Kohashi S, Hasegawa K, Okawa Y, Sano H, Takada A, Sato H. Evaluation of malignancy using Ki-67 labeling index for gastric stromal tumor. Gastric Cancer. 2003;6(3):168-72. doi: 10.1007/s10120-003-0246-3. PMID: 14520530.

26. Wong NA, Young R, Malcomson RD, Nayar AG, Jamieson LA, Save VE, Carey FA, Brewster DH, Han C, Al-Nafussi A. Prognostic indicators for gastrointestinal stromal tumours: a clinicopathological and immunohistochemical study of 108 resected cases of the stomach. Histopathology. 2003;43(2):11826. doi: 10.1046/j.1365-2559.2003.01665.x. PMID: 12877726.

27. Belev B, Brčić I, Prejac J, Golubić ZA, Vrbanec D, Božikov J, Alerić I, Boban M, Razumović JJ. Role of Ki67 as a prognostic factor in gastrointestinal stromal tumors. World J Gastroenterol. 2013;19(4):523-7. doi: 10.3748/wjg.v19.i4.523. PMID: 23382631; PMCID: PMC3558576. 
28. Kemmerling R, Weyland D, Kiesslich T, Illig R, Klieser E, Jäger T, Dietze O, Neureiter D. Robust linear regression model of Ki-67 for mitotic rate in gastrointestinal stromal tumors. Oncol Lett. 2014;7(3):745-749. doi: 10.3892/ol.2014.1802. PMID: 24527082; PMCID: PMC3919875.

29. Shin Y, Hyeon J, Lee B, Ha SY, Hong ME, Do IG, Kim KM. PHH3 as an Ancillary Mitotic Marker in Gastrointestinal Stromal Tumors. J Pathol Transl Med. 2015;49(1):23-9. doi: 10.4132/jptm.2014.10.08. PMID: 25812654; PMCID: PMC4357403.

30. Wang M, Grissmann B, Marx A, et al. Abstract 3420: Expression and significance of proliferation markers phosphohistone $\mathrm{H} 3, \mathrm{Ki}-67 / \mathrm{MIB}-1$, and survivin in gastrointestinal stromal tumors [J]. Cancer Research, 2015, 75(15 Supplement): 3420-3420.

31. Ottmann K, Tronnier M, Mitteldorf C. Detection of mitotic figures in thin melanomasimmunohistochemistry does not replace the careful search for mitotic figures in hematoxylin-eosin stain. J Am Acad Dermatol. 2015;73(4):637-44. doi: 10.1016/j.jaad.2015.07.007. PMID: 26278815.

32. Colman H, Giannini C, Huang L, Gonzalez J, Hess K, Bruner J, Fuller G, Langford L, Pelloski C, Aaron J, Burger $\mathrm{P}$, Aldape $\mathrm{K}$. Assessment and prognostic significance of mitotic index using the mitosis marker phospho-histone $\mathrm{H} 3$ in low and intermediate-grade infiltrating astrocytomas. Am J Surg Pathol. 2006;30(5):657-64. doi: 10.1097/01.pas.0000202048.28203.25. PMID: 16699322.

33. Fukushima S, Terasaki M, Sakata K, Miyagi N, Kato S, Sugita Y, Shigemori M. Sensitivity and usefulness of anti-phosphohistone-H3 antibody immunostaining for counting mitotic figures in meningioma cases. Brain Tumor Pathol. 2009;26(2):51-7. doi: 10.1007/s10014-009-0249-9. PMID: 19856215.

34. Casper DJ, Ross KI, Messina JL, Sondak VK, Bodden CN, McCardle TW, Glass LF. Useof antiphosphohistone $\mathrm{H} 3$ immunohistochemistry to determine mitotic rate in thin melanoma. Am J Dermatopathol. 2010;32(7):650-4. doi: 10.1097/DAD.0b013e3181cf7cc1. PMID: 20559123.

35. Idriss MH, Kazlouskaya V, Malhotra S, Andres C, Elston DM. Phosphohistone-H3 and Ki-67 immunostaining in cutaneous pilar leiomyoma and leiomyosarcoma (atypical intradermal smooth muscle neoplasm). J Cutan Pathol. 2013;40(6):557-63. doi: 10.1111/cup.12127. PMID: 23550775.

36. Fletcher CD, Berman JJ, Corless C, Gorstein F, Lasota J, Longley BJ, Miettinen M, O'Leary TJ, Remotti H, Rubin BP, Shmookler B, Sobin LH, Weiss SW. Diagnosis of gastrointestinal stromal tumors: A consensus approach. Hum Pathol. 2002;33(5):459-65. doi: 10.1053/hupa.2002.123545. PMID: 12094370.

37. Joensuu H. Risk stratification of patients diagnosed with gastrointestinal stromal tumor. Hum Pathol. 2008;39(10):1411-9. doi: 10.1016/j.humpath.2008.06.025. PMID: 18774375.

38. Miettinen M, Lasota J. Gastrointestinal stromal tumors: pathology and prognosis at different sites. Semin Diagn Pathol. 2006;23(2):70-83. doi: 10.1053/j.semdp.2006.09.001. PMID: 17193820.

\section{Figures}




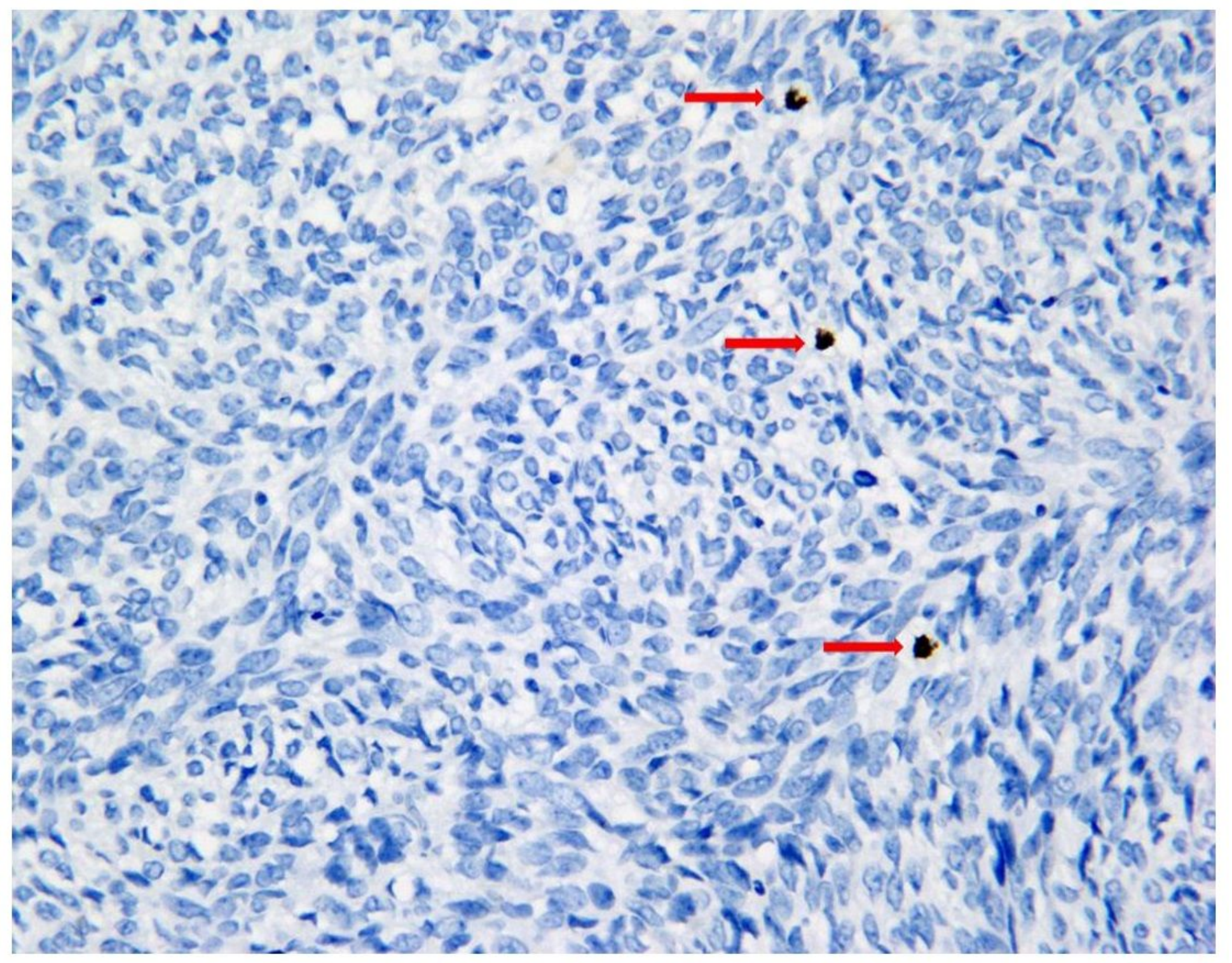

Figure 1

PHH3 was positive in nuclei of GIST tumor cells (red arrow, $\times 40$ ). 


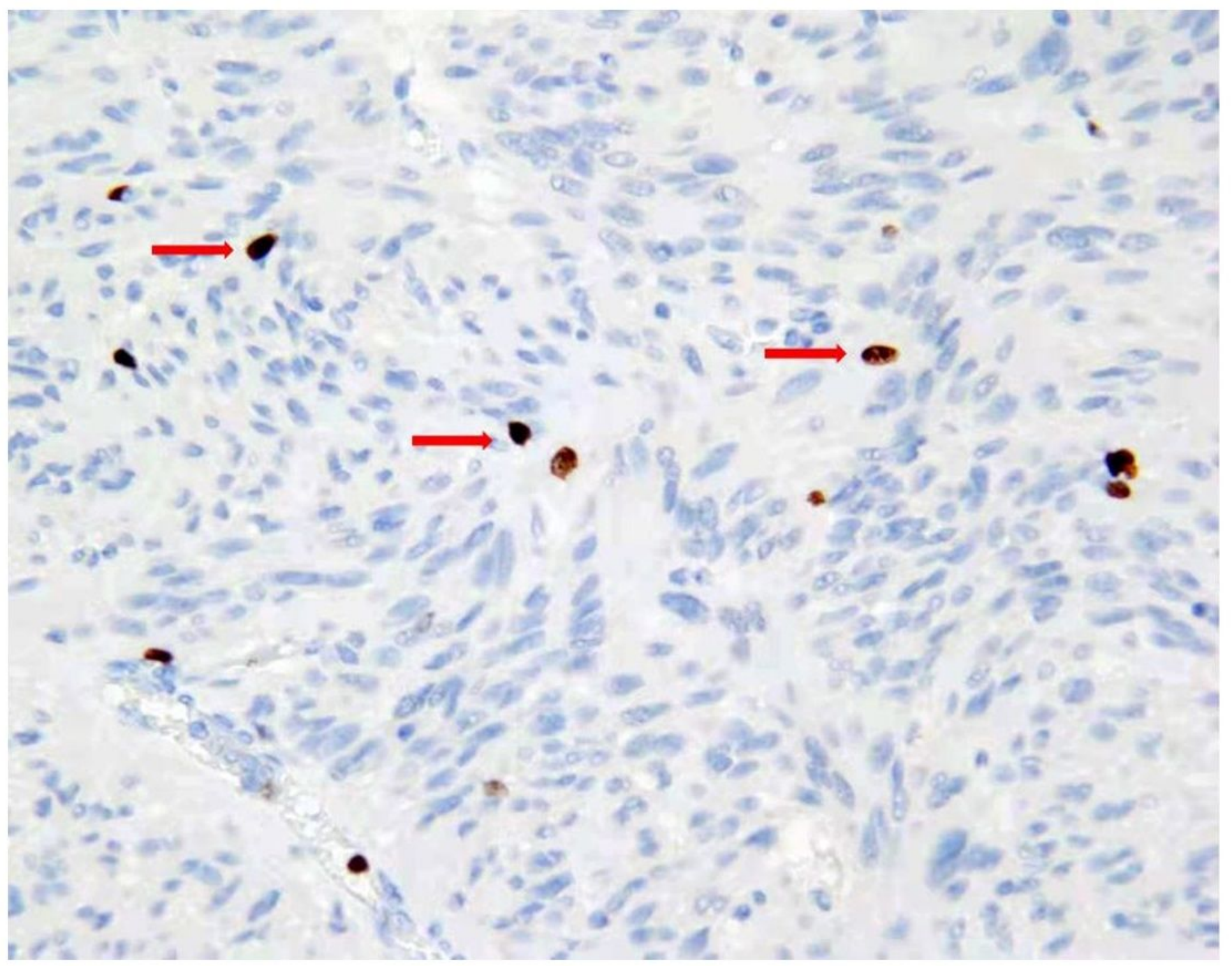

Figure 2

Ki67 was positive in nuclei of GIST tumor cells (red arrow, $\times 40$ ). 